\title{
MAPPING THE WETLAND VEGETATION COMMUNITIES OF THE AUSTRALIAN GREAT ARTESIAN BASIN SPRINGS USING SAM, MTMF AND SPECTRALLY SEGMENTED PCA HYPERSPECTRAL ANALYSES
}

\author{
D. C. White*, M. M. Lewis
}

CORRESPONDING AUTHOR: *Davina C. White, Postdoctoral Research Fellow, Landscape Futures Program, The Environment Institute, The University of Adelaide, South Australia, E-mail: davina.white@adelaide.edu.au, Tel.: +61 (0)8 8303 8112, Fax.: +61 (0)8 83036717.

TECHNICAL SESSION: Technical Commission VII, WG VII/3

KEY WORDS: Hyperspectral, Environment, Ecosystem, Analysis, Vegetation; Monitoring; Spectral

\begin{abstract}
:
The Australian Great Artesian Basin (GAB) supports a unique and diverse range of groundwater dependent wetland ecosystems termed GAB springs. In recent decades the ecological sustainability of the springs has become uncertain as demands on this iconic groundwater resource increase. The impacts of existing water extractions for mining and pastoral activities are unknown. This situation is compounded by the likelihood of future increasing demand for extractions.
\end{abstract}

Hyperspectral remote sensing provides the necessary spectral and spatial detail to discriminate wetland vegetation communities. Therefore the objectives of this paper are to discriminate the spatial extent and distribution of key spring wetland vegetation communities associated with the GAB springs evaluating three hyperspectral techniques: Spectral Angle Mapper (SAM), Mixture Tuned Matched Filtering (MTMF) and Spectrally Segmented PCA. In addition, to determine if the hyperspectral techniques developed can be applied at a number of sites representative of the range of spring formations and geomorphic settings and at two temporal intervals.

Two epochs of HyMap airborne hyperspectral imagery were captured for this research in March 2009 and April 2011 at a number of sites representative of the floristic and geomorphic diversity of GAB spring groups/complexes within South Australia. Colour digital aerial photography at $30 \mathrm{~cm}$ GSD was acquired concurrently with the HyMap imagery. The image acquisition coincided with a field campaign of spectroradiometry measurements and a botanical survey.

To identify key wavebands which have the greatest capability to discriminate vegetation communities of the GAB springs and surrounding area three hyperspectral data reduction techniques were employed: (i) Spectrally Segmented PCA (SSPCA); (ii) the Minimum Noise Transform (MNF); and (iii) the Pixel Purity Index (PPI). SSPCA was applied to NDVI-masked vegetation portions of the HyMap imagery with wavelength regions spectrally segmented for the VIS-NIR (450-1,350 nm), SWIR 1 (1,400-1,800 nm) and SWIR $2(1,950-2,480 \mathrm{~nm})$. The resulting pure endmember image pixels of the vegetation communities identified were used as target spectra for input into the SAM and MTMF algorithms.

Spring wetland vegetation communities successfully discriminated include low lying reeds and sedges along spring tails (Baumea spp. and Cyperus spp.), dense homogenous stands of Phragmites australis reeds, and sporadic patches of salt couch grass (Sparabolus spp.).

Our results indicate that a combination of hyperspectral remote sensing techniques which reduce superfluous wavebands providing a targeted spectral matching approach are capable of discriminating and mapping key vegetation communities of the GAB springs. This approach provides reliable baseline mapping of the GAB spring wetland vegetation communities, with repeatability over space and time. In addition it has the capability to determine the sensitivity of spring wetland vegetation extent, distribution and diversity, to associated changes in spring flow rates due to water extractions. This approach will ultimately inform water allocation plan management policies.

\section{INTRODUCTION}

\subsection{Background}

The Australian Great Artesian Basin (GAB) supports a unique and diverse range of groundwater dependent wetland ecosystems termed GAB springs, which contain a number of rare and relic endemic flora and fauna (Fensham and Fairfax,
2003; Gotch et. al., 2008; Ponder, 2004). The GAB springs are of great national and international importance for their ecological, scientific and economic values, and are culturally significant to indigenous Australians (Ah Chee, 2002). They have historically provided a vital source of water in the inland heart of Australia (Badman et. al., 1996; Boyd, 1990; Mudd, 2000). In recent decades the ecological sustainability of the

* Corresponding author. 
springs has become uncertain as demands on this iconic groundwater resource increase. The impacts of existing water extractions for mining and pastoral activities are unknown. This situation is compounded by the likelihood of future increasing demand for extractions.

Despite their importance, GAB springs have received scant inventory and documentation of their vegetation extent, distribution and composition. Hyperspectral remote sensing provides the necessary spectral and spatial detail to discriminate wetland vegetation communities and has shown great potential in previous studies for mapping wetlands vegetation (Torbick and Becker, 2009; Hestir et al., 2008; Zomer et al., 2009). This technology will enable accurate and repeatable baseline and longer-term mapping of these remote and spatially disparate groundwater dependent ecosystems (GDEs) to be achieved.

The objectives of this paper are to discriminate the spatial extent and distribution of key spring wetland vegetation communities associated with the GAB springs evaluating Spectral Angle Mapper (SAM), Mixture Tuned Matched Filtering (MTMF) and Spectrally Segmented Principal Component Analysis (PCA) hyperspectral techniques. In addition, to determine if the hyperspectral techniques developed can be applied at a number of sites representative of the range of spring formations, their floristic and geomorphic diversity and at two temporal intervals (March 2009 and April 2011).

\subsection{Study area}

The GAB springs found in South Australia (SA) are located along the western margin of the GAB and are formed from the natural outflow of groundwater. The GAB springs surface expression is composed of wetland vegetation, saline flats and carbonaceous substrate. The wetland plant communities of GAB springs vary between spring groups (cluster of springs sharing the same water source) and complexes (clusters of spring groups which share the same geomorphological settings), some of which are rare, relic and endemic to this region. This paper focuses on three sites Hermit Hill Springs complex (latitude $29.60^{\circ} \mathrm{S}$ and longitude $137.41^{\circ} \mathrm{E}$ ), Freeling Springs, Mount Denison complex (latitude $28.06^{\circ} \mathrm{S}$ and longitude $135.91^{\circ} \mathrm{E}$ ), and Dalhousie Springs complex (latitude 26.45 $\mathrm{S}$ and longitude $135.51^{\circ} \mathrm{E}$ ). The three sites are representative of GAB springs within SA. The sites also differ in their geomorphic setting, vegetation community composition, spatial extent and distribution of springs.

\section{MATERIALS AND METHODS}

\subsection{Image Data}

Two epochs of HyMap airborne hyperspectral mosaicked image cubes were captured for this research in March 2009 and April 2011. The two epochs of HyMap imagery were captured under dry antecedent conditions (March 2009) and wet antecedent conditions (April 2011). The HyMap imagery is composed of 126 wavebands with a bandwidth of $\sim 15 \mathrm{~nm}$ and wavelength range of $450-2,500 \mathrm{~nm}$, a $\sim 3 \mathrm{~m}$ ground sampling distance (GSD), and swath width of $1.5 \mathrm{~km}$. The raw HyMap imagery was radiometrically corrected along with geometric correction and colour balancing of swaths to form a seamless mosaic (Kruse et al., 2009; Cocks et al., 1998). Colour digital aerial photography at $30 \mathrm{~cm}$ GSD was acquired concurrently with the HyMap imagery.
Results discussed in this paper focus on the March 2009 baseline image capture for all three sites. More detailed comparison of changes between March 2009 and April 2011 is focused on the Hermit Hill springs complex.

\subsection{Field data}

The image acquisition coincided with a field campaign of spectroradiometry measurements and a botanical survey, which included recording vegetation cover and composition within $9 \times$ $9 \mathrm{~m}$ sample plots representative of the range of spring vegetation types and cover. The spatial locations of field measurements were recorded with GPS.

\subsection{Image processing}

To identify key wavebands which have the greatest capability to discriminate vegetation communities of the GAB springs and surrounding area three hyperspectral data reduction techniques were employed: (i) the Minimum Noise Transform (MNF); (ii) the Pixel Purity Index (PPI); and (iii) Spectrally Segmented PCA (SSPCA). SSPCA was applied to NDVI-masked vegetation portions of the HyMap imagery with wavelength regions spectrally segmented for the VIS-NIR $(450-1,350 \mathrm{~nm})$, SWIR 1 (1,400-1,800 nm) and SWIR 2 (1,950-2,480 nm). The pure pixels identified from the SAM and MTMF analyses were interactively verified as specific spring vegetation communities using spatial location and attribute data collected from the botanical survey plots overlayed onto colour composites of the HyMap imagery, MNF and PPI output images. The resulting pure endmember image pixels of the vegetation communities identified were used as target spectra for input into the SAM and MTMF algorithms which identify pixels within the HyMap image which are spectrally similar to the target spectra.

\section{RESULTS AND DISCUSSION}

The resulting SAM and MTMF output images of the identified target vegetation communities are currently being validated through formal accuracy assessment using field observations and digital colour aerial photography. Spring wetland vegetation communities successfully discriminated include low lying reeds and sedges along spring tails (Baumea spp., Cyperus spp., Fimbristylis sp., Gahnia trifida sp.), dense homogenous stands of Phragmites australis reeds and White Tea Tree (Melaleuca glomerata sp.). In addition sporadic patches of salt couch grass (Sparabolus spp.), Samphire shrublands (Haloscarcia sp. and Sarcocrina sp.), and Sea Heath (Frankenia sp.), which fringe the springs were also discriminated.

VIS-NIR PCs 2, 3 and 9 identified key vegetation discrimination wavelength features, in particular, the green peak at $555 \mathrm{~nm}$, chlorophyll absorption feature at $685 \mathrm{~nm}$, VIS-NIR and red-edge contrasts. The SWIR 1 PC 3 mapped Phragmites australis, with notable loadings at wavelengths 1,450, 1,645$1,715,1815$, and $1,825 \mathrm{~nm}$ associated with water, lignin, and cellulose absorptions, respectively. The SWIR 2 region revealed little spectral variation (White and Lewis, 2010).

Differences between March 2009 and April 2011 HyMap image captures focused on the Hermit Hill springs complex. The extent and distribution of spring wetland vegetation communities varied between the two image dates. Most notable were decreases in Phragmites australis reeds in contrast with 
increases in spring tail and fringe vegetation (Cyperus spp., Sparabolus spp.).

\section{CONCLUSIONS}

Our results indicate that a combination of hyperspectral remote sensing techniques which reduce superfluous wavebands providing a targeted spectral matching approach are capable of discriminating and mapping key vegetation communities of the GAB springs. This approach provides reliable baseline mapping of the GAB spring wetland vegetation communities, with repeatability over space and time. In addition it has the capability to determine the sensitivity of spring wetland vegetation extent, distribution and diversity, to associated changes in spring flow rates due to water extractions. This approach will ultimately inform water allocation plan management policies.

\section{REFERENCES}

Ah Chee, D., 2002. Kwatye, Indigenous peoples connection with kwatye (water) in the Great Artesian Basin. Environment SA, 9, pp. 20-21.

Badman, F. J., Pickering, R. E. and Middleton, B. M., 1996. Environmental monitoring and management at the Olympic Dam Copper/Uranium Mine. In: Mulligan, D. R. (Ed) Environmental management in the Australian minerals and energy industries - principles and practice. UNSW Press and Australian Minerals and Energy Environment Foundation (AMEEF), Melbourne, Australia, pp. 468-495.

Boyd, W. E., 1990. Mound Springs. In: Tyler MJ, Twidale CR, Davies M, Wells CB (eds) Natural history of the north east Deserts. Royal Society of South Australia, Adelaide, Australia, pp. 107-118.

Cocks, T., Jenssen, R., Stewart, A., Wilson, I. and Shields, T., 1998. The HyMap airborne hyperspectral sensor: the system, calibration and performance, In: Proceedings of the $1^{\text {st }}$ EARSeL Workshop on Imaging Spectroscopy, Eds. Schaepman, M., Schläpfer, D. and Itten, K. I., pp. 37-43.

Fensham, R. J. and Fairfax, R. J., 2003. Spring wetlands of the Great Artesian Basin, Queensland, Australia. Wetlands Ecology and Management, 11, pp. 343-362.

Gotch, T. B., Adams, M., Murphy, N. P., Austin, A. D., 2008. A molecular systematic overview of wolf spiders associated with Great Artesian Springs in South Australia: evolutionary origins and an assessment of metapopulation structure in two species. Invertebrate Systematics, 22, pp 151 - 165.

Hestir, E. L., Khanna, S., Andrew, M. E., Santos, M. J., Viers, J. H., Greenberg, J. A., Rajapakse, S. S. and Ustin, S. L., 2008. Identification of invasive vegetation using hyperspectral remote sensing in the California Delta ecosystem, Remote Sensing of Environment, 112, pp. 4034-4047.

Kruse, F. A., Boardman, J. W., Lefkoff, A. B., Young, J. M. and Kierein-Young, K. S., 2000. HyMap: an Australian hyperspectral sensor solving global problems - results from USA HyMap data acquisitions, In: Proceedings of the International Conference Australasian Remote Sensing and Photogrammetry, 18-23. Available from http://www.hyvista.com/technology/sensors 09/02/2009].

[accessed:

Mudd, G. M., 2000. Mound springs of the Great Artesian Basin in South Australia: a case study from Olympic Dam, Environmental Geology, 39(5), pp. 463-476.

Ponder, W. F., 2004. Endemic aquatic macroinvertebrates of artesian springs of the Great Artesian Basin-progress and future directions. Records of the South Australian Museum Monograph Series, 7, pp. 101-110.

Torbick, N. and Becker, B., 2009. Evaluating Principal Components Analysis for identifying optimal bands using wetland hyperspectral measurements from the Great Lakes, USA, Remote Sensing, 1(3), pp. 208-417.

White, D. and Lewis, M.M., 2010. Mapping the spectral and spatial characteristics of mound spring wetland vegetation in South Australia: A novel spectrally segmented PCA approach. Proceedings American Society for Photogrammetry and Remote Sensing Annual Conference. San Diego, California, USA.

Zomer, R. J., Trabucco, A., Ustin, S. L., 2009. Building spectral libraries for wetlands land cover classification and hyperspectral remote sensing, Journal of Environmental Management, 90, pp. 2170-2177.

\section{ACKNOWLEDGEMENTS}

The research presented in this paper was sponsored by the National Water Commission under its Raising National Water Standards program as part of the Allocating water and maintaining springs in the Great Artesian Basin project. The authors would also like to acknowledge the partner organisations of the project: South Australian Arid Lands Natural Resource Management Board (SAALNRMB); Department for Water (DFW); Department of Environment and Natural Resources (DENR); Commonwealth Scientific and Research Organisation (CSIRO); Finders University; and The University of Adelaide. We would also like to warmly thank the traditional owners and native title holders along with pastoral land owners for permitting access to their land; HyVista for acquiring the HyMap hyperspectral airborne imagery; Mr Travis Gotch, ecology chief investigator for his expert knowledge of the GAB springs in SA; and everyone who has assisted with field data collection. 